\section{Kidney \\ Blood Pressure Research}

\title{
Arterial Stiffness and Walk Time in Patients with End-Stage Renal Disease
}

\author{
Abbi D. Lane Pei-Tzu Wu $^{\mathrm{b}}$ Brandon Kistler ${ }^{\mathrm{b}}$ Peter Fitschen ${ }^{\mathrm{b}} \quad$ Emily Tomayko $^{\mathrm{b}}$ \\ Jin-Hee Jeong ${ }^{b}$ Hae Ryung Chung ${ }^{b}$ Huimin Yan $^{b}$ Sushant M. Ranadive ${ }^{b}$ Shane \\ Phillips $^{\mathrm{a}}$ Bo Fernhalla Kenneth Wilund ${ }^{\mathrm{b}}$
}

aUniversity of Illinois at Chicago, Chicago, IL, USA; 'University of Illinois at Urbana-Champaign, Urbana, IL, USA

\author{
Key Words \\ Arterial stiffness $\bullet$ Shuttle walk $\bullet$ ESRD
}

\begin{abstract}
Background: End-stage renal disease patients experience increased prevalence of cardiovascular disease. Heart-artery interaction may be shifted, impacting blood pressure lability, and exercise tolerance. The coupling ratio consists of the ratio of indexed arterial elastance (EaI, arterial load) to ElvI, a measure of cardiac contractility or stiffness. Our purpose was to explore the relationship between elastances and functional capacity. We hypothesized that arterial stiffness (central pulse wave velocity, PWV) and elastances would be correlated to shuttle walk time. Methods: We used applanation tonometry, ultrasonography, and a shuttle walk test to evaluate our hypothesis. Spearman's correlations were used to assess relationships between variables. Block regression was also performed. Results: Forty-two subjects on maintenance hemodialysis participated. Average age $=44 \pm 5$ years, body surface area $=2.01$ $\mathrm{kg} / \mathrm{m}^{2}$. Mean $\mathrm{EaI}=4.45$ and mean ElvI $=6.89$; the coupling ratio $=0.82$. Mean aortic pulse pressure $=51 \mathrm{mmHg}$ and $\mathrm{PWV}=9.6 \mathrm{~m} / \mathrm{s}$. $\mathrm{PWV}(\mathrm{r}=-0.385)$ and $\mathrm{EaI}(\mathrm{r}=-0.424)$ were significantly and inversely related to walking time while stroke volume index (SVI) was positively correlated to shuttle walk time $(r=0.337), p<0.05$ for all. Conclusions: We conclude that, like other clinical populations, both arterial and heart function predict walking ability and represent potential targets for intervention; arterial stiffness and SVI are strongly related to shuttle walk time in patients with ESRD.
\end{abstract}

Copyright (c) 2013 S. Karger AG, Basel

\section{Introduction}

The incidence of cardiovascular disease (CVD) and mortality is increased in patients with chronic kidney disease (CKD) [1] and end-stage renal disease (ESRD) [1-3]. This patient 


\section{Kidney Blood Pressure Research}

Kidney Blood Press Res 2013;37:142-150

DOI: 10.1159/000350068

Publisnea onine: April 30, 2013

C 2013 S. Karger AG, Basel

www.karger.com/kbr

Lane/Wu/Kistler/Fitschen/Tomayko/Jeong/Chung/Yan/Ranadive/Phillips/Fernhall/ Wilund: Arterial Stiffness and Walking Time in ESRD

population also has a high prevalence of hypertension and augmented left ventricular work compared to healthy adults of the same age [1]. The hypertension-induced stiffening of both the heart and arteries in ESRD increases the workload imposed on the heart and consequently alters cardiac performance [2]. This may also alter the coupling of the left ventricle and vascular system, an important consideration as the ventricular-vascular interaction is associated with mortality [4] and can provide important information on cardiac load and energetics [5], but this outcome has not been fully explored in this population.

Ventricular-vascular coupling [6] quantifies the workload imposed on the ventricle by the entire arterial tree [7], and can be expressed as the ratio of arterial elastance (Ea) to left ventricular elastance (Elv). Increased Ea/Elv can be physically attributed to stiffer arteries and reduced cardiac compliance or decreased systolic function [8, 9]. Changes in Ea are also a consequence of physiological factors affecting the arterial load, including: total peripheral resistance, characteristic impedance, total arterial compliance, and diastolic time [10]. Likewise, changes in left ventricular (LV) elastance occur not only because of changes in structure, but also because of altered contractility and metabolic factors affecting cardiac energetics [11]. This interaction may be of particular importance to individuals with ESRD as the coupling ratio is pivotal for maintaining blood pressure homeostasis and reducing pressure lability in response to fluid and volume shifts, a hallmark of ESRD [5].

Appropriate ventricular and vascular matching is crucial in preventing exacerbated myocardial ischemia in response to reduced perfusion due to blood volume changes [5] and has been linked to survival post-infarction in patients with CVD [4]. Importantly, coronary flow reserve has already been shown to be compromised in ESRD, and functional capacity is also limited in other clinical populations by elevated Ea/Elv [12-14]. Thus, there may be a relationship between Ea/Elv and measures of physical capability in patients with ESRD. This could be important in understanding potential hemodynamic mechanisms involved in the manifestation of functional limitations as well as CVD mortality in these patients. This is of particular importance to this population, as only $13.2 \%$ of patients with ESRD report reaching recommended levels of physical activity [15]. Additionally, low levels of exercise and physical activity may further contribute to the prevalence of CVD in patients with ESRD.

We examined ventricular-vascular coupling, arterial stiffness and functional walking ability in patients with end-stage renal disease. Our purpose was to evaluate the relationship of these physiologic variables to measured functional performance. We hypothesized that ESRD patients will exhibit increased Ea/Elv ratios and central stiffness, and that these changes will be related to functional performance in this patient population.

\section{Materials and Methods}

\section{Subjects}

Forty-two patients on maintenance hemodialysis (16 females, 26 males) were recruited from the Champaign-Urbana Dialysis Clinic and the University of Illinois at Chicago dialysis clinic (Champaign, IL and Chicago, IL). Patients were screened for eligibility with a health and medical history questionnaire. All participants gave written informed consent and this study was approved by the University of Illinois Institutional Review Board, and the protocol complied with Declaration of Helinski. Inclusion criteria for participation in this study included the following: 1) End stage renal disease and on dialysis; 2) an age of 30-70 years; 3) a BMI less than $35 \mathrm{~kg} / \mathrm{m}^{2}$; 4) medical clearance from a primary care physician. Subjects were excluded if they had chronic obstructive pulmonary disease (COPD), coronary heart failure (CHF), or cardiovascular surgery (e.g., coronary bypass, valve replacement, or angioplasty) in the past 6 months.

\section{Anthropometrics}

Standing height and weight measurements were completed with participants wearing light-weight clothing using a stadiometer and balance-beam scale. 


\section{Kidney Blood Pressure Research}

Kidney Blood Press Res 2013;37:142-150

\begin{tabular}{l|l}
\hline DOI: $10.1159 / 000350068$ & (C) 2013 S. Karger AG, Basel
\end{tabular}

Published onIIne: April 30, 2013

www.karger.com/kbr

Lane/Wu/Kistler/Fitschen/Tomayko/Jeong/Chung/Yan/Ranadive/Phillips/Fernhall/ Wilund: Arterial Stiffness and Walking Time in ESRD

Brachial artery blood pressure assessment

Resting systolic BP (SBP) and diastolic BP (DBP) were measured at the brachial artery using an automated oscillometric cuff (HEM-907 XL; Omron, Shimane, Japan). Brachial BP was taken in duplicate. If the two values were not within $5 \mathrm{~mm} \mathrm{Hg}$, another measurement was taken until 2 values within $5 \mathrm{mmHg}$ of each other were obtained. Values within $5 \mathrm{~mm} \mathrm{Hg}$ of each other were averaged and used for analysis. Endsystolic pressure (ESP) was calculated from the equation $0.9 \times$ SBP [7] .

Pulse contour analysis

Radial artery pressure waveforms were obtained in the supine position from a 10-s epoch using applanation tonometry (Millar Instruments, Houston, TX) and calibrated with brachial blood pressure (BP) obtained from a standard sphygmamonometer. Using a generalized validated transfer function [16], a central aortic pressure waveform was reconstructed from the radial artery pressure waveform (SphygmoCor; AtCor Medical, Sydney, Australia) to obtain central BP. Aortic mean arterial pressure and aortic pulse pressure [4] were determined from the integration of the reconstructed aortic pressure waveform using the SphygmoCor software. This technique has been validated for use in obtaining central pressure [16]. The sub-endocardial viability index (SEVR) was derived from the reconstructed waveform and is defined as the ratio of the area under the diastolic portion of the curve to the systolic area under the curve in the recreated central pulse waveform [17]. Both aortic pulse pressure (aPP) and SEVR are determined, at least in part, by heart and large artery interaction.

\section{Pulse Wave Velocity}

Central pulse wave velocity was calculated from the waveform at the carotid and femoral (central) site. All waveforms were found on the right side of the body using applanation tonometry (except when the presence of a fistula required acquisition of waveforms from the opposite side of the body) (SphygmoCor; AtCor Medical, Sydney, Australia) and described in detail elsewhere [18].

\section{Echocardiography}

Cardiac output (CO), stroke volume, and end systolic volume (ESV) were assessed by two-dimensional echocardiography using an Aloka alpha-10 system (Tokyo, Japan). With subjects in the left lateral position, measurements were obtained using the four-chamber apical view. The interior of the left ventricle was traced manually during both end systole and end diastole. Volumes were measured using Simpson's rule. Stroke volume (SV) was calculated by subtracting end-diastolic volume (EDV) from ESV. CO was calculated as heart rate (HR) multiplied by SV. Three beats were measured and the average of the measurement was used in the analysis. All analyzed values were normalized for body surface area (BSA) using DuBois's formula [19]. Ejection fraction was calculated from the ventricular volumes and expressed as a percentage of ESV to EDV. Left ventricular mass (LVM) was determined using the Penn convention from M-mode images taken at the parasternal long-axis using methodology described in detail elsewhere [20].

\section{Calculation of Arterial and Ventricular Elastances and Ea/Elv}

Arterial elastance (EaI) was calculated as end-systolic pressure (ESP), determined from the SphygmoCor, divided by stroke volume index (SVI, SVI=SV/BSA). Left ventricular elastance (ElvI) was calculated as ESP/ end-systolic volume index (ESVI, ESVI=ESV/BSA). The indexed volumes were used because body size affects these measures [10]. The ratio of EaI/ElvI represents indexed ventricular-vascular coupling.

\section{Shuttle Walk Test}

Physical performance was measured by distance walked during an incremental shuttle walk test (ISWT). The ISWT is a progressive test in which patients walk back and forth continuously over a 10 meter course. The walking speed is paced by a series of beeps that signal when the subject should have completed the 10 meter walk. The pace is progressively increased so that the walking speed at the end of each successive minute is $\geq$ to: $1.12,1.54,1.88,2.26,2.64,3.02,3.4,3.78$ miles per hour. The test was terminated when the subject was unable to complete the $10 \mathrm{~m}$ course before the subsequent beep. The ISWT was performed on non-dialysis days, 18 to 30 hours after a previous dialysis session. 


\section{Kidney \\ Blood Pressure Research}

Table 1. Subject Characteristics

\begin{tabular}{lc}
\hline & (n) \\
\hline Smoking & \\
Current & 12 \\
Previous & 18 \\
Never & 12 \\
Hypertension & \\
Controlled & 39 \\
Uncontrolled & 1 \\
Normotensive & 2 \\
Reason for Terminating Walk Test & \\
Fatigue & 8 \\
Leg Pain & 2 \\
Inability to Maintain Pace & 32 \\
Diabetes & \\
Type I & 1 \\
Type II & 13 \\
None & 28 \\
\hline
\end{tabular}

\section{Kidney Blood Press Res 2013;37:142-150}

\begin{tabular}{l|l}
\hline DOI: $10.1159 / 000350068$ & (C) 2013 S. Karger AG, Basel
\end{tabular}

Published onlıne: April 30, 2013

www.karger.com/kbr

ane/Wu/Kistler/Fitschen/Tomayko/Jeong/Chung/Yan/Ranadive/Phillips/Fernhall/ Wilund: Arterial Stiffness and Walking Time in ESRD
Table 2. Cardiac Characteristics

\begin{tabular}{lcc}
\hline Variable & Mean & Standard Deviation \\
\hline SVI $\left(\mathrm{ml} / \mathrm{m}^{2}\right)^{*}$ & 35.2 & 2.3 \\
ESVI $\left(\mathrm{ml} / \mathrm{m}^{2}\right)$ & 24.1 & 1.7 \\
COI $\left(\mathrm{l} / \mathrm{min} / \mathrm{m}^{2}\right)^{*}$ & 2.6 & 1.5 \\
LVMI $\left(\mathrm{g} / \mathrm{m}^{2}\right)$ & 225 & 87 \\
SEVR $(\%)$ & 131.54 & 5 \\
EaI $\left(\mathrm{mmHg} \mathrm{m}^{2} / \mathrm{ml}\right)^{*}$ & 4.45 & 2.5 \\
ElvI $\left(\mathrm{mmHg} \mathrm{m}^{2} / \mathrm{ml}\right)$ & 6.89 & 4.1 \\
EaI/ElvI & 0.82 & 0.7 \\
Shuttle walk time (s) & 251 & 120 \\
\hline SVI $=$ stroke volume indexed to body size, ESVI = end- \\
systolic volume indexed to body size, COI = cardiac \\
output indexed to body size, LVMI = left ventricular \\
mass indexed to body size, SEVR = sub-endocardial \\
viability ratio, EaI = arterial elastance indexed to body \\
Size, ElvI = ventricular elastance indexed to body size, \\
EaI/ElvI =the indexed coupling ratio, Shuttle walk \\
time = amount of time walked during shuttle test, \\
*denotes a significant correlation to shuttle walk time, \\
p<0.05.
\end{tabular}

Statistical Analysis

Descriptive statistics are presented as mean \pm standard error. Normality of distribution was assessed by using Shapiro-Wilk tests, and extreme outliers were removed before further analysis. Pearson's and Spearman's correlations were used to assess relationships between normally and non-normally distributed variables, respectively. Block regression was performed to examine the significance of individual arterial and cardiac variables to walking time; block 1 consisted of arterial variables (Ea, aPP, MAP, PWV) while block 2 contained ventricular variables (ElvI, SVI, COI, HR). We then performed the same block regression as previously described but added a third block for age in order to account for independent effects of aging upon walk time. Significance was set a $\mathrm{p}<0.05$. Analysis was performed using Statistical Package for the Social Sciences (SPSS) version 19.0 (Chicago, IL).

\section{Results}

\section{Subject Characteristics}

This study includes a total of 42 subjects. Mean age was $44 \pm 5 \mathrm{yrs}$, and average BSA was $2.01 \pm 0.04 \mathrm{~kg} / \mathrm{m}^{2}$. The average vintage was $51 \pm 42$ months (range $=1-177$ months). Other subject characteristics are presented in Table 1.

Blood Pressures and Arterial Stiffness

Average brachial MAP was $95 \pm 15 \mathrm{mmHg}$, SBP was $137 \pm 3 \mathrm{mmHg}$ and DBP was $75 \pm 2$ mmHg. Mean aortic MAP, SBP and DBP were $93 \pm 2,127 \pm 4$ and $75 \pm 4$ mmHg respectively. The mean central PWV was $9.6 \pm 0.6 \mathrm{~m} / \mathrm{s}$.

\section{Cardiac Variables and Elastances}

Cardiac variables and elastances are shown in Table 2.

\section{Correlations}

Shuttle walk time was inversely correlated to EaI ( $\mathrm{r}=-0.424)$, central PWV $(r=-0.385)$ and positively related to both indexed cardiac output $(\mathrm{r}=0.442)$ and indexed stroke volume $(\mathrm{r}=0.337$, Figure $1 \mathrm{C}), \mathrm{p}<0.05$ for all. The relationships between EaI and PWV and shuttle walk time are illustrated in Figure $1 \mathrm{~A}$ and $\mathrm{B}$. The relationships between shuttle walk time and $\mathrm{PWV} / \mathrm{MAP}(\mathrm{r}=-0.297)$ and aortic pulse pressure (aPP, $\mathrm{r}=-0.276)$ did not reach significance, $\mathrm{p}=0.06$ for both. There were no significant relationships between shuttle walk time and HR $(r=-0.061)$, SEVR $(r=-0.298)$, ElvI $(r=-0.218)$, or the coupling ratio $(r=-0.041), p>0.05$. 


\section{Kidney \\ Blood Pressure Research}

Kidney Blood Press Res 2013;37:142-150

\begin{tabular}{l|l}
\hline DOI: $10.1159 / 000350068$ & C 2013 S. Karger AG, Basel
\end{tabular}

Published onlıne: April 30, 2013

www.karger.com/kbr

146
Regression

Our block regression revealed that SVI $(\beta=3.114, p=0.013)$ and PWV $(\beta=-11.187$, $\mathrm{p}=0.036$ ) were significant determinants of shuttle walk time. When we controlled for age in our block regression, PWV remained a significant predictor of walk time, $\beta=-14.68$ and $\mathrm{p}<0.012$.

\section{Discussion}

Our study generated several new and novel findings. Patients with ESRD in this cohort have an average Ea/ELV of 0.82 . This value is not different from the 0.5 to 1.0 range found in a healthy population, suggesting ventricular-arterial coupling is maintained in a normal range [7]. However, the individual components, EaI and ElvI, were much higher than values observed in a healthy population, most likely due to the prevalence of hypertension and resultant increased endsystolic stiffness and reduction in cardiac performance observed in patients with ESRD [21]. In support of this notion, our group's average ejection fraction was 49\%, which is above the clinical cut-off for heart failure (40\%) but less than the mean ejection fraction of $60-70 \%$ of a young, healthy heart.

We also found a significant and inverse relationship between shuttle walk time and EaI,as well as shuttle walk time and central PWV, and a positive correlation of both COI and SVI with shuttle walk time. This suggests that higher levels of arterial load and stiffness negatively affect functional shuttle walk ability whereas higher stroke volume positively affects shuttle walk ability in this population. The age of the patient did affect our correlations, but the relationship between central arterial stiffness and walking time remained. This suggests that although age of the patient may impact some measures of arterial stiffness, and thus, affect

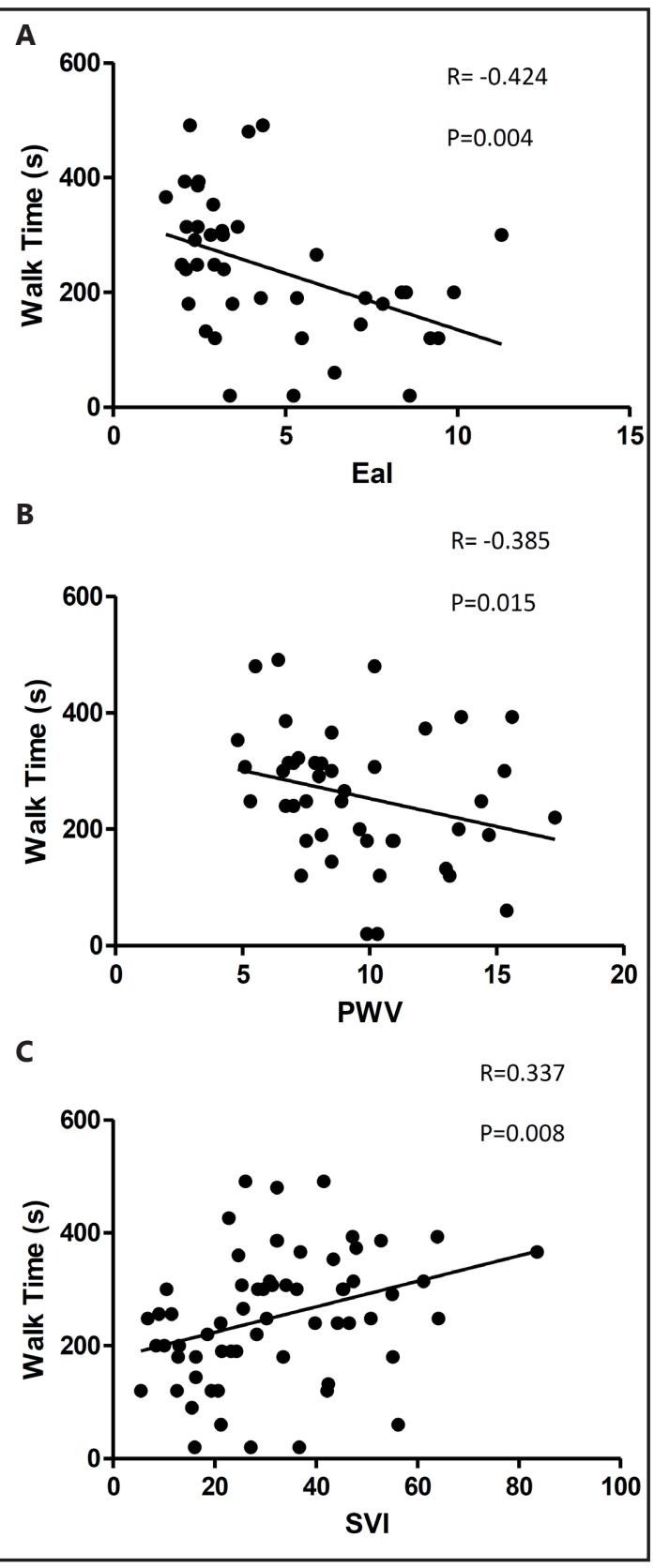

Fig. 1. A, B, and C. EaI and central PWV are inversely related to walking time in ESRD while SVI is directly correlated to shuttle walk time. walking ability, arterial stiffness itself is a predictor of walk time independent of age.

Previous work has compared heart function of ESRD patients to that of patients with heart failure [22]. Borlaug, et al. also report upon the importance of global cardiovascular reserve and its impact on ventricular-vascular interaction and exercise performance in heart failure [23]. The heart failure patients in this prior study exhibited impairment in many aspects of cardiovascular performance: chronotropic incompetence, endothelial dysfunction, vasodilation, and impaired contractility all contributed to reduced exercise tolerance [23]. This finding may be extended to understand the constellation of factors also affecting exercise tolerance in patients with ESRD. Our patients had very high resting EaI 


\section{Kidney Blood Pressure Research}

Kidney Blood Press Res 2013;37:142-150

\begin{tabular}{l|l}
\hline DOI: $10.1159 / 000350068$ & (C) 2013 S. Karger AG, Basel
\end{tabular}

Publisned on Ine: AprII 30, 2013

www.karger.com/kbr

Lane/Wu/Kistler/Fitschen/Tomayko/Jeong/Chung/Yan/Ranadive/Phillips/Fernhall/ Wilund: Arterial Stiffness and Walking Time in ESRD

and ElvI, themselves integrated measures of total arterial and heart function. Therefore, we may speculate that there is little ability to further augment arterial/ventricular elastance in order to accommodate physical work, i.e., walking. This study reinforces the idea that there is a cardiovascular phenotype common to patients with heart failure and ESRD. Along this line, left ventricular hypertrophy, caused by arterial resistance heightened by hypertension is also common in patients with heart failure with preserved ejection fraction. Left ventricular hypertrophy may reduce myocardial efficiency and compromise exercise tolerance (perhaps by reducing SV) in both populations. Our cohort does suffer from clinical levels of left ventricular hypertrophy [24]; clinical LVH is diagnosed at $106 \mathrm{~g} / \mathrm{m}^{2}$ for women and $114 \mathrm{~g} / \mathrm{m}^{2}$ for men, and our cohort's mean left ventricular mass index was greater than the established cut-off.

Amplified pulse waves caused by arterial stiffness have been found in normotensive patients with CKD [20]. Earlier work has shown that patients with early CKD also exhibit decreased aortic distensibility [22]. Furthermore, the reduction in aortic compliance was correlated to attenuated glomerular filtration rate [22] and increased incidence of vascular calcification in CKD [25]. Our data on patients with ESRD are consistent with these earlier reports showing increased arterial stiffness and arterial load in this patient population. Furthermore, markers of central stiffness and arterial load were predictors of shuttle walk time in this population. This relationship between arterial stiffness and walking ability has also been demonstrated in patients with other cardiovascular diseases, such as peripheral arterial disease [26, 27], and adds to the similarities between ESRD patients and other types of CVD. Our data add to the growing body of literature supporting the inclusion of measures of arterial stiffness in exams and as targets for intervention in order to improve quality of life for individuals with ESRD.

COI and SVI were directly related to shuttle walk time in this study. Because HR was not related to walking time ( $p>0.05)$, we propose that the ability of a more compliant arterial system may allow generation of a higher SV and this may lead to the ability to increase functional walking ability. The results of the multiple regression analysis support this notion, as SVI and PWV were the only variables retained as significant predictors of walking time, explaining $27 \%$ of the variance. Considering that stiff arteries result in increased afterload thus impeding ejection, this may affect the ability of the left ventricle to generate sufficient SV [8] and distribute blood to the periphery. This is a plausible physiologic explanation for the association between SVI, EaI, central PWV and walking time.

Further support for this notion is provided by Chantler et al. [28], who concluded that, in a large and apparently healthy subject population, there is an inverse relationship between EaI and the use of the Frank-Starling mechanism during exercise, such that individuals with the highest EaI also had the lowest SVI and EDVI [28]. In contrast to this study, our cohort was evaluated only at rest. It does appear, though, that patients with ESRD cannot offset reductions in SV by increasing arterial $\mathrm{O}_{2}$ extraction, as was the case of the group healthy adults in the study by Chantler et al. Consistent with patients with ESRD, patients with heart failure also have peripheral limitations that contribute to reduced capacity during exercise tasks [29], and these are compounded by limited arterial-venous $\mathrm{O}_{2}$ extraction [30]. Hence, exercise tolerance is low and skeletal muscle atrophy, weakness, and fatigue all contribute to this endpoint. Low exercise tolerance, skeletal muscle atrophy, weakness and fatigue are also prominent features in ESRD, and previous work suggests that patients with ESRD, like those with heart failure, are also limited by peripheral $0_{2}$ extraction ability [31].

Central arterial stiffness is a strong prognostic indicator of cardiovascular mortality in renal patients [32]. It also correlates more directly to the load imposed on the left ventricle by arterial stiffness as it represents the immediate impedance to ejection [33]. For this reason, central PWV is a more important mediator of ventricular-vascular coupling than is brachial pressure, and these data support the idea that it can also affect blood delivery and impact exercise tolerance. When controlled for MAP, the relationship between central PWV and walking time lost significance $(\mathrm{p}=0.06)$, perhaps suggesting that other structural physiological alterations (such as central calcification) are primarily pressure-driven 


\section{Kidney \\ Blood Pressure Research}

Kidney Blood Press Res 2013;37:142-150

\begin{tabular}{l|l}
\hline DOI: $10.1159 / 000350068$ & C 2013 S. Karger AG, Basel
\end{tabular}

Published online: April 30, 2013

www.karger.com/kbr

Lane/Wu/Kistler/Fitschen/Tomayko/Jeong/Chung/Yan/Ranadive/Phillips/Fernhall/ Wilund: Arterial Stiffness and Walking Time in ESRD

determinants of walking time in our cohort. This also indicates that there is a pressuredriven shift of load onto the stiffer collagen versus more compliant elastin fibers within the arterial wall [34], opposing ventricular ejection. Not surprisingly, the average central PWV of this group of patients with ESRD is higher than the established norm of $7.2 \mathrm{~m} / \mathrm{s}$ that one would expect in an otherwise healthy population of similar age [13].

The physiologic and structural arterial stiffening described previously should also cause an augmentation of aortic pulse pressure [4]. Both aPP and PWV have prognostic value in cardiovascular disease, and are recognized as cardiovascular risk factors in hypertensive and CKD patients $[13,25]$. Increased PWV is also correlated to compromised renal function in CKD $[35,36]$ and plays a role in mediating the pulsatile component of EaI through its effect on SV. Though we did not find a significant relationship between aPP and shuttle walk time, we did find predictive value in EaI, an integrated measure of total arterial load that includes time intervals, peripheral resistance, and aortic impedance. However, arterial stiffness and SVI appear to be the most important cardiovascular mediators of walking time in ESRD.

\section{Future Directions and Study Limitations}

Both the heart and arteries are functionally affected by ESRD. Because exercise interventions have been successful in improving ventricular capabilities in coronary artery disease populations [37], individuals in heart failure [5], and ESRD patients, [38, 39] further investigation should examine the potential role ventricular and vascular cross-talk may play in mediating both overall cardiovascular morbidity as well as functional improvement in ESRD . Indeed, in other patients whose walking ability is also related to arterial stiffness (patients with peripheral arterial disease), a home-based walking program improved both mobility and quality of life [40], and a 12-week exercise intervention attenuated overall cardiovascular morbidity and mortality [41].

The response of the ERSD patient to endurance exercise has not been completely elucidated. Future studies may explore the role of exercise training in reducing ventricular and vascular stiffness in order to enhance functional abilities, reduce cardiovascular events, and improve quality of life in ESRD.

A few limitations of this study should be noted: we used the equation $0.9 \times$ SBP to estimate end-systolic pressure, an equation that has been validated at rest in other populations but not specifically tested in ESRD [7]. We also estimated $V_{0}$ to be equal to zero and non-invasively measured cardiac volumes. It is also important to note that this is a cross-sectional study, and correlation (not causation) is reported.

\section{Conclusion}

EaI, and central PWV are inversely related to physical performance (shuttle walk time) in individuals with ESRD, while SVI is positively related to shuttle walk time. This is similar to the cardiovascular phenotype in other clinical populations where augmented arterial stiffness adversely affects exercise and functional performance. This study highlights the importance of managing the mediating influence of arterial stiffening on functional capacity in individuals with ESRD and suggests a role for exercise as therapy in this population as well.

\section{Conflict of Interests}

The authors of this study have no conflict of interests to report. 


\section{Kidney \\ Blood Pressure Research}

\section{Acknowledgements}

This study was funded the National Institute of Health, NIH (RO1 DK084016-01 to K. Wilund). The authors of this study have no conflicts of interest to report, and the results presented here have not been published elsewhere.

\section{References}

1 Meisinger C, Doring A, Lowel H: Chronic kidney disease and risk of incident myocardial infarction and allcause and cardiovascular disease mortality in middle-aged men and women from the general population. Eur Heart J 2006;27:1245-1250.

-2 O'Rourke MF, Yaginuma T, Avolio AP: Physiological and pathophysiological implications of ventricular/ vascular coupling. Ann Biomed Eng 1984;12:119-134.

-3 Ritz E, Zeier M, Schneider P, Jones E: Cardiovascular mortality of patients with polycystic kidney disease on dialysis: Is there a lesson to learn? Nephron 1994;66:125-128.

4 Antonini-Canterin F, Enache R, Popescu BA, Popescu AC, Ginghina C, Leiballi E, Piazza R, Pavan D, Rubin D, Cappelletti P, Nicolosi GL: Prognostic value of ventricular-arterial coupling and b-type natriuretic peptide in patients after myocardial infarction: A five-year follow-up study. J Am Soc Echocardiogr 2009;22:12391245.

-5 Kass DA: Ventricular arterial stiffening: Integrating the pathophysiology. Hypertension 2005;46:185-193.

-6 Antonini-Canterin F, Carerj S, Di Bello V, Di Salvo G, La Carrubba S, Vriz O, Pavan D, Balbarini A, Nicolosi GL: Arterial stiffness and ventricular stiffness: A couple of diseases or a coupling disease? A review from the cardiologist's point of view. Eur J Echocardiogr 2009;10:36-43.

7 Chantler PD, Lakatta EG, Najjar SS: Arterial-ventricular coupling: Mechanistic insights into cardiovascular performance at rest and during exercise. J Appl Physiol 2008;105:1342-1351.

-8 Cohen-Solal A, Caviezel B, Himbert D, Gourgon R: Left ventricular-arterial coupling in systemic hypertension: Analysis by means of arterial effective and left ventricular elastances. J Hypertens 1994;12:591-600.

-9 London GM: The concept of ventricular/vascular coupling: Functional and structural alterations of the heart and arterial vessels go in parallel. Nephrol Dial Transplant 1998;13:250-253.

$>10$ Little WC, Cheng CP: Effect of exercise on left ventricular-arterial coupling assessed in the pressure-volume plane. Am J Physiol 1993;264:H1629-1633.

-11 Starling MR: Left ventricular-arterial coupling relations in the normal human heart. Am Heart J 1993;125:1659-1666.

$>12$ Little WC, Pu M: Left ventricular-arterial coupling. J Am Soc Echocardiogr 2009;22:1246-1248.

13 Determinants of pulse wave velocity in healthy people and in the presence of cardiovascular risk factors: 'Establishing normal and reference values'. Eur Heart J 2010;31:2338-2350.

14 Wong RC, Dumont CA, Austin BA, Kwon DH, Flamm SD, Thomas JD, Starling RC, Desai MY: Relation of ventricular-vascular coupling to exercise capacity in ischemic cardiomyopathy: A cardiac multi-modality imaging study. Int J Cardiovasc Imaging 2010;26:151-159.

15 Painter P, Ward K, Nelson RD: Self-reported physical activity in patients with end stage renal disease. Nephrol Nurs J 2011;38:139-147; quiz 148.

-16 Holland DJ, Sacre JW, McFarlane SJ, Coombes JS, Sharman JE: Pulse wave analysis is a reproducible technique for measuring central blood pressure during hemodynamic perturbations induced by exercise. Am J Hypertens 2008;21:1100-1106.

17 Chemla D, Nitenberg A, Teboul JL, Richard C, Monnet X, le Clesiau H, Valensi P, Brahimi M: Subendocardial viability index is related to the diastolic/systolic time ratio and left ventricular filling pressure, not to aortic pressure: An invasive study in resting humans. Clin Exp Pharmacol Physiol 2009;36:413-418.

18 Van Bortel LM, Duprez D, Starmans-Kool MJ, Safar ME, Giannattasio C, Cockcroft J, Kaiser DR, Thuillez C: Clinical applications of arterial stiffness, task forceIII: Recommendations for user procedures. Am J Hypertens 2002;15:445-452.

19 DuBois D, DuBois E: A formula to estimate the approximate surface area if height and weight be known. Arch Intern Med 1916;17:8. 


\section{Kidney \\ Blood Pressure Research}

Kidney Blood Press Res 2013;37:142-150

DOI: 10.1159/000350068 $\quad$ C 2013 S. Karger AG, Basel

Published onlIne: April 30, 2013

www.karger.com/kbr

Lane/Wu/Kistler/Fitschen/Tomayko/Jeong/Chung/Yan/Ranadive/Phillips/Fernhall/ Wilund: Arterial Stiffness and Walking Time in ESRD

20 Devereux RB, Reichek N: Echocardiographic determination of left ventricular mass in man. Anatomic validation of the method. Circulation 1977;55:613-618.

21 London GM: Left ventricular alterations and end-stage renal disease. Nephrol Dial Transplant 2002;17 Suppl 1:29-36.

-22 Edwards NC, Ferro CJ, Townend JN, Steeds RP: Aortic distensibility and arterial-ventricular coupling in early chronic kidney disease: A pattern resembling heart failure with preserved ejection fraction. Heart 2008;94:1038-1043.

-23 Borlaug BA, Olson TP, Lam CS, Flood KS, Lerman A, Johnson BD, Redfield MM: Global cardiovascular reserve dysfunction in heart failure with preserved ejection fraction. J Am Coll Cardiol 2010;56:845-854.

24 Levy D, Garrison RJ, Savage DD, Kannel WB, Castelli WP: Prognostic implications of echocardiographically determined left ventricular mass in the framingham heart study. New Engl J Med 1990;322:1561-1566.

25 Piper HM, Kasseckert SA, Schluter KD, Abdallah Y: [pathophysiology of myocardial reperfusion injury]. Dtsch Med Wochenschr 2008;133:586-590.

-26 Brewer LC, Chai HS, Bailey KR, Kullo IJ: Measures of arterial stiffness and wave reflection are associated with walking distance in patients with peripheral arterial disease. Atherosclerosis 2007;191:384-390.

27 Ahimastos AA, Dart AM, Lawler A, Blombery PA, Kingwell BA: Reduced arterial stiffness may contribute to angiotensin-converting enzyme inhibitor induced improvements in walking time in peripheral arterial disease patients. J Hypertens 2008;26:1037-1042.

-28 Chantler PD, Melenovsky V, Schulman SP, Gerstenblith G, Becker LC, Ferrucci L, Fleg JL, Lakatta EG, Najjar SS: Use of the frank-starling mechanism during exercise is linked to exercise-induced changes in arterial load. Am J Physiol Heart Circ Physiol 2012;302:H349-358.

29 Bhella PS, Prasad A, Heinicke K, Hastings JL, Arbab-Zadeh A, Adams-Huet B, Pacini EL, Shibata S, Palmer MD, Newcomer BR, Levine BD: Abnormal haemodynamic response to exercise in heart failure with preserved ejection fraction. Eur J Heart Fail 2011;13:1296-1304.

-30 Haykowsky MJ, Brubaker PH, John JM, Stewart KP, Morgan TM, Kitzman DW: Determinants of exercise intolerance in elderly heart failure patients with preserved ejection fraction. J Am Coll Cardiol 2011;58:265-274.

-31 Painter P: Determinants of exercise capacity in ckd patients treated with hemodialysis. Adv Chronic kidney Dis 2009;16:437-448.

32 Guerin AP, Pannier B, Marchais SJ, London GM: Cardiovascular disease in the dialysis population: Prognostic significance of arterial disorders. Curr Opin Nephrol Hypertens 2006;15:105-110.

33 Kass DA: Age-related changes in venticular-arterial coupling: Pathophysiologic implications. Heart Fail Rev 2002;7:51-62.

-34 Armentano RL, Levenson J, Barra JG, Fischer EI, Breitbart GJ, Pichel RH, Simon A: Assessment of elastin and collagen contribution to aortic elasticity in conscious dogs. Am J Physiol 1991;260:H1870-1877.

-35 Cassidy SC, Chan DP, Allen HD: Left ventricular systolic function, arterial elastance, and ventricular-vascular coupling: A developmental study in piglets. Pediatr Res 1997;42:273-281.

36 Prince CT, Secrest AM, Mackey RH, Arena VC, Kingsley LA, Orchard TJ: Augmentation pressure and subendocardial viability ratio are associated with microalbuminuria and with poor renal function in type 1 diabetes. Diab Vasc Dis Res 2010;7:216-224.

-37 Doreau A, Belot A, Bastid J, Riche B, Trescol-Biemont MC, Ranchin B, Fabien N, Cochat P, Pouteil-Noble C, Trolliet P, Durieu I, Tebib J, Kassai B, Ansieau S, Puisieux A, Eliaou JF, Bonnefoy-Berard N: Interleukin 17 acts in synergy with b cell-activating factor to influence b cell biology and the pathophysiology of systemic lupus erythematosus. Nat Immunol 2009;10:778-785.

-38 Koh KP, Fassett RG, Sharman JE, Coombes JS, Williams AD: Effect of intradialytic versus home-based aerobic exercise training on physical function and vascular parameters in hemodialysis patients: A randomized pilot study. Am J Kidney Dis 2010;55:88-99.

39 Couto CI: Exercise training improves cardiovascular fitness in people receiving haemodialysis for chronic renal disease. J Physiother 2012;58:130.

40 Collins TC, Lunos S, Carlson T, Henderson K, Lightbourne M, Nelson B, Hodges JS: Effects of a home-based walking intervention on mobility and quality of life in people with diabetes and peripheral arterial disease: A randomized controlled trial. Diabetes care 2011;34:2174-2179.

41 Sakamoto S, Yokoyama N, Tamori Y, Akutsu K, Hashimoto H, Takeshita S: Patients with peripheral artery disease who complete 12-week supervised exercise training program show reduced cardiovascular mortality and morbidity. Circ J 2009;73:167-173. 